\title{
Complete response with fotemustine and bevacizumab after early progression following radiotherapy and temozolomide treatment in patient with glioblastoma multiforme
}

\author{
Ovidio Fernández Calvo, María Eva Pérez López, Jesús García Gómez \\ Department of Medical Oncology, Ourense University Hospital, 32005 Ourense, Spain.
}

Correspondence to: Dr. Ovidio Fernández Calvo, Department of Medical Oncology, Ourense University Hospital, 54 Ramon Puga Street, 32005

Ourense, Spain. E-mail: ovidiofernandezcalvo@yahoo.es

\section{A B S T R A C T}

Glioblastoma multiforme is the most common type of primary central nervous system tumor and is noted for its short survival and poor response to chemotherapeutic agents. Unfortunately, the relapse rate is very high, and there is no reference drug for second-line treatment. In this study, a patient was treated with the Soffietti regimen. The induction phase was fotemustine $75 \mathrm{mg} / \mathrm{m}^{2}$ at day 1 and day 8 and bevacizumab $10 \mathrm{mg} / \mathrm{kg}$ at day 1 and day 15 . The maintenance phase was fotemustine $75 \mathrm{mg} / \mathrm{m}^{2}$ and bevacizumab $10 \mathrm{mg} / \mathrm{kg}$ every 3 weeks for two cycles. Follow-up magnetic resonance imaging showed post-surgical changes at the left occipital level, without contrast enhancement, and toxic left leuko-encephalopathy post-treatment without mass effect and with no evidence of tumor residue. The patient then was maintained with bevacizumab monotherapy until it was withdrawn when pulmonary thromboembolism occurred. Following tumor regrowth, fotemustine was started again as maintenance therapy. The patient achieved stabilization of his disease until his death due to thromboembolic and infectious complications.

Key words: Bevacizumab, brain tumor, fotemustine

\section{Introduction}

Glioblastoma multiforme (GBM) is the most common type of primary central nervous system (CNS) tumor and is noted for its short survival and poor response to chemotherapeutic agents. ${ }^{[1]}$ Adjuvant temozolomide and radiotherapy is the gold-standard treatment. ${ }^{[2]}$ Unfortunately, the relapse rate is very high, and there is no reference drug for second-line treatment. ${ }^{[3-5]}$

\section{Case Report}

This report describes the case of a 58-year-old patient with a history of hypertriglyceridemia and psoriasis who was admitted to the emergency department after a 4-day episode of disorientation to time and place, speech disturbance, 2/5 lack of muscle strength, right hemi-temporal blindness, and motor dysphasia. Chest, abdominal, and pelvic computed tomography was unremarkable. A brain magnetic resonance imaging (MRI) showed an oval left parieto-occipital lesion with the anteroposterior diameter of $27 \mathrm{~mm}$, nodular contrast medium enhancement and white matter edema. In February 2011, the lesion was resected and

\begin{tabular}{|l|l|}
\hline \multicolumn{2}{|c|}{ Access this article online } \\
\hline Quick Response Code: & Website: \\
\hline & www.jcmtjournal.com \\
\cline { 2 - 2 } & \\
\hline
\end{tabular}

was diagnosed as a WHO grade 4 GBM, with a $30 \%$ mind bomb E3 ubiquitin-ligase 1 proliferation index.

In March 2011, external radiotherapy (total dose 60 Gy, fractioned in 2 Gy/day) was started with concomitant temozolomide at $75 \mathrm{mg} / \mathrm{m}^{2} /$ day, followed by temozolomide monotherapy $\left(150 \mathrm{mg} / \mathrm{m}^{2}\right.$ for 5 days each 28 day circle in the first cycle, and $200 \mathrm{mg} / \mathrm{m}^{2}$ in the second cycle). Thereafter, an episode of gait imbalance with motor disturbance of the right upper limb occurred.

Three months after finishing radiotherapy, a brain MRI showed a cystic left parieto-occipital lesion measuring $40 \mathrm{~mm} \times 40 \mathrm{~mm} \times 30 \mathrm{~mm}$, and edema. This MRI suggested tumor relapse [Figure 1a].

The patient rejected surgery and chemotherapy according to the Soffietti et al. ${ }^{[6]}$ regimen was started. The induction phase was fotemustine $75 \mathrm{mg} / \mathrm{m}^{2}$ at day 1 and day 8 and bevacizumab $10 \mathrm{mg} / \mathrm{kg}$ at day 1 and day 15 , followed by an interval of 3 weeks, and maintenance phase: fotemustine $75 \mathrm{mg} / \mathrm{m}^{2}$ and bevacizumab $10 \mathrm{mg} / \mathrm{kg}$, every 3 weeks for two cycles. Follow-up MRI showed post-surgical changes at the left occipital level, without contrast enhancement, toxic left leuko-encephalopathy post-treatment, without mass effect and with no evidence of tumor residue [Figure 1b]. There was a clinical response and from a radiological point of view, the mass had disappeared and there was no contrast enhancement (Response Assessment in Neuro-Oncology criteria were used to assess this). ${ }^{[7]}$ The patient was discharged on a physiological replacement dose of corticosteroids and maintenance bevacizumab monotherapy. 


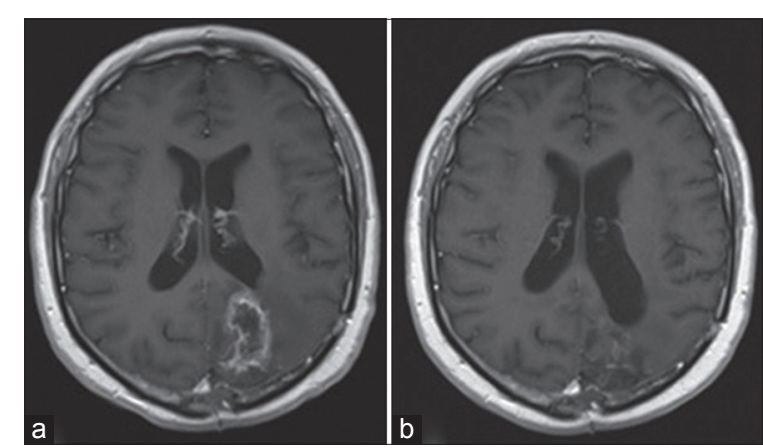

Figure 1: (a) Magnetic resonance imaging 3 months after finishing radiotherapy during temozolomide monotherapy; (b) response after two cycles of fotemustine and bevacizumab treatment

In April 2012, pulmonary thromboembolism occurred, and the bevacizumab was withdrawn. Low molecular weight heparin treatment was initiated. Two months later, repeat MRI showed a $2.5 \mathrm{~cm}$ enhancement area in the surgical site, suggesting tumor relapse. In June 2012, fotemustine was restarted as monotherapy at $75 \mathrm{mg} / \mathrm{m}^{2}$ every 3 weeks (two cycles). In August 2012, MRI showed tumor stabilization. In November 2012, the patient suffered bronchoaspiration and unfortunately died.

\section{Discussion}

Fotemustine is a third-generation nitrosourea with alkylating cytotoxic activity and high lipophilicity that allows it to cross the blood-brain barrier. It achieves therapeutic levels in the CNS and has proven antitumor activity, either as monotherapy or in combination..$^{[5,8-10]}$ Bevacizumab is a humanized monoclonal antibody that inhibits vascular endothelial growth factor and has activity in distinct tumors like GBM, either in monotherapy or combination with irinotecan. ${ }^{[11,12]}$ The combination of these two drugs has shown promising results. Soffietti et al. ${ }^{[6]}$ published the results of a phase II study in which fotemustine and bevacizumab were combined according to the following scheme: induction phase (fotemustine $75 \mathrm{mg} / \mathrm{m}^{2}$ at day 1 and day 8, and bevacizumab $10 \mathrm{mg} / \mathrm{kg}$ at day 1 and day 15); followed by an interval of 3 weeks, and maintenance phase (fotemustine $75 \mathrm{mg} / \mathrm{m}^{2}$ and bevacizumab $10 \mathrm{mg} / \mathrm{kg}$, every 3 weeks) until tumor progression, unacceptable toxicity, or withdrawal of consent. The combination of these two drugs showed promising results: overall response rate was $52 \%$, and a significant neurologic improvement was observed in $60 \%$ of symptomatic patients. Progression-free survival at 6 months was $42.6 \%$, and overall survival at 6 months was $75.9 \%$. Median progression-free survival was 5.2 months, and median overall survival was 9.1 months. Toxicity ${ }^{[6]}$ with this regimen was predictable and manageable; grade 1 or 2 appeared in the majority of patients. Neutropenia (13\%), thrombocytopenia (9\%), wound dehiscence (5.5\%), and deep venous thrombosis (4\%) are the main grade 3 toxicities. Pulmonary embolism appeared as grade 4 toxicity in $4 \%$ of patients. These results encouraged us to use this therapeutic regimen in our patient.
The early initial progression, occurring shortly after the second adjuvant temozolomide cycle, made us consider a scheme that could achieve a high rate of disease control. The outstanding response obtained at 4 months of treatment with fotemustine plus bevacizumab, without radiological evidence from the pre-existing tumor mass, prompted us to continue with bevacizumab maintenance. ${ }^{[12]}$ When this patient had received temozolomide monotherapy, he presented with instability and vertiginous symptoms. During bevacizumab and fotemustine therapy, the neurological symptoms disappeared. The withdrawal of bevacizumab after 7 months of treatment, due to pulmonary thromboembolism, caused a relapse of the disease. Nonetheless, the patient achieved stabilization of the disease from reintroduction of fotemustine until his death due to thromboembolic and infectious complications.

We consider this case interesting because treatment with bevacizumab plus fotemustine achieved rapid response, in 4 months, in a patient with rapid progression to first-line treatment. Furthermore, it is notable because the patient responded to treatment with fotemustine after the progression that occurred following withdrawal of bevacizumab maintenance.

We consider that this combination scheme should be tested in further clinical trials. Due to the promising results reported by Soffietti et al., and confirmed by our own clinical experience, fotemustine should be considered as rescue treatment for relapsed GBM.

\section{References}

1. Levin VA, Leibel SA, Gutin PH. Neoplasms of the central nervous system. In: DeVita VT Jr, Hellman S, Rosenberg SA, editors. Cancer: Principles and Practice of Oncology. 6th ed. Philadelphia: Lippincott Williams and Wilkins; 2001. p. 2100-60.

2. Stupp R, Hegi ME, Mason WP, van den Bent MJ, Taphoorn MJ, Janzer RC, Ludwin SK, Allgeier A, Fisher B, Belanger K, Hau P, Brandes AA, Gijtenbeek J, Marosi C, Vecht CJ, Mokhtari K, Wesseling P, Villa S, Eisenhauer E, Gorlia T, Weller M, Lacombe D, Cairncross JG, Mirimanoff RO. European Organisation for Research and Treatment of Cancer Brain Tumour and Radiation Oncology Groups; National Cancer Institute of Canada Clinical Trials Group. Effects of radiotherapy with concomitant and adjuvant temozolomide versus radiotherapy alone on survival in glioblastoma in a randomised phase III study: 5-year analysis of the EORTC-NCIC trial. Lancet Oncol 2009;10:459-66.

3. Friedman HS, Prados MD, Wen PY, Mikkelsen T, Schiff D, Abrey LE, Yung WK, Paleologos N, Nicholas MK, Jensen R, Vredenburgh J, Huang J, Zheng M, Cloughesy T. Bevacizumab alone and in combination with irinotecan in recurrent glioblastoma. J Clin Oncol 2009;27:4733-40.

4. Perry JR, Bélanger K, Mason WP, Fulton D, Kavan P, Easaw J, Shields C, Kirby S, Macdonald DR, Eisenstat DD, Thiessen B, Forsyth P, Pouliot JF. Phase II trial of continuous dose-intense temozolomide in recurrent malignant glioma: RESCUE study. J Clin Oncol 2010;28:2051-7.

5. Fabrini MG, Silvano G, Lolli I, Perrone F, Marsella A, Scotti V, Cionini L. A multi-institutional phase II study 
on second-line Fotemustine chemotherapy in recurrent glioblastoma. J Neurooncol 2009;92:79-86.

6. Soffietti R, Trevisan E, Bertero L, Cassoni P, Morra I, Fabrini MG, Pasqualetti F, Lolli I, Castiglione A, Ciccone G, Rudà R. Bevacizumab and fotemustine for recurrent glioblastoma: a phase II study of AINO (Italian Association of Neuro-Oncology). J Neurooncol 2014;116:533-41.

7. Wen PY, Macdonald DR, Reardon DA, Cloughesy TF, Sorensen AG, Galanis E, DeGroot J, Wick M, Gilbert MR, Lassman $\mathrm{AB}$, Tsien $\mathrm{C}$, Mikkelsen $\mathrm{T}$, Wong ET, Chamberlain MC, Stupp R, Lamborn KR, Vogelbaum MA, van der Bent MJ, Chang SM. Updated response assessment criteria for high-grade gliomas: response assessment in neuro-oncology working group. J Clin Oncol 2010;28:1963-72.

8. Silvani A, Lamperti E, Gaviani P, Eoli M, Fiumani A, Salmaggi A, Falcone C, Filippini G, Botturi A, Boiardi A. Salvage chemotherapy with procarbazine and fotemustine combination in the treatment of temozolomide treated recurrent glioblastoma patients. J Neurooncol 2008;87:143-51.

9. Gaviani P, Salmaggi A, Silvani A. Combined chemotherapy with temozolomide and fotemustine in recurrent glioblastoma patients. J Neurooncol 2011;104:617-8.
10. Addeo R, Caraglia M, De Santi MS, Montella L, Abbruzzese A, Parlato C, Vincenzi B, Carraturo M, Faiola V, Genovese M, Cennamo G, Del Prete S. A new schedule of fotemustine in temozolomide-pretreated patients with relapsing glioblastoma. J Neurooncol 2011;102:417-24.

11. Friedman HS, Prados MD, Wen PY, Mikkelsen T, Schiff D, Abrey LE, Yung WK, Paleologos N, Nicholas MK, Jensen R, Vredenburgh J, Huang J, Zheng M, Cloughesy T. Bevacizumab alone and in combination with irinotecan in recurrent glioblastoma. J Clin Oncol 2009;27:4733-40.

12. Reardon DA, Herndon JE 2nd, Peters K, Desjardins A, Coan A, Lou E, Sumrall A, Turner S, Sathornsumetee S, Rich JN, Boulton S, Lipp ES, Friedman HS, Vredenburgh JJ. Outcome after bevacizumab clinical trial therapy among recurrent grade III malignant glioma patients. $J$ Neurooncol 2012;107:213-21.

How to cite this article: Calvo OF, López MEP, Gómez JG. Complete response with fotemustine and bevacizumab after early progression following radiotherapy and temozolomide treatment in patient with glioblastoma multiforme. J Cancer Metastasis Treat 2015;1:36-8.

Received: 24-10-2014; Accepted: 23-02-2015.

Source of Support: Nil, Conflict of Interest: None declared. 